\title{
The International Economy of Children's rights: issues in translation
}

\author{
Dr John I'Anson, Faculty of Social Sciences, University of Stirling \\ Professor Ann Quennerstedt, Institute for Humanities, Örebro University \\ Dr Carol Robinson, Education Research Centre, University of Brighton
}

Accepted for publication in The International Journal of Children's Rights by Brill.

\begin{abstract}
The United Nations Convention on the Rights of the Child (UNCRC) is an international legal text that necessitates multiple translations into national policy contexts if it is to become mobilised within professional practice. The aim of this paper is to foreground this process of translation and to identify some of the limitations inherent within present mobilisations of the UNCRC. On the basis of this diagnosis, we then raise a series of ethical considerations that might inform a more critical and open-ended approach.
\end{abstract}

We characterise current approaches to mobilising the UNCRC as an international economy of rights and we represent this diagrammatically. This economy, we contend, involves multiple translations of the UNCRC text into a series of performative demands to which adults become accountable in situations of professional practice with children and young people.

We then critically analyse this economy as presently instituted and point to a number of inherent limitations. We argue that a failure to address the issue of 
translation from legal text to relational practice has led to a technical resolution. The potential challenge of the UNCRC as an authoritative text of critique is further weakened by the promotion of a consensus thinking that privileges agreement over the complexities associated with ethical thinking. In the light of this critique, the paper identifies new lines of questioning to inform debate concerning how a children's rights agenda might be refracted differently in future.

Key Words: UNCRC, translation, international economy of rights, ethics, morality, technicalization, responsibility, consensus. 


\section{Introduction}

It is now over twenty-five years since the United Nations Convention on the Rights of the Child (UNCRC) (United Nations, 1989) was formally adopted by the United Nations General Assembly. Since that time, 195 nation states have ratified the Convention, which comprises 54 substantive Articles pertaining to children's rights. The UNCRC is an international legal text and is therefore instituted across the world. Various accountability agendas are in play to monitor the effectiveness of its implementation in the diverse sites where adults' practice intersects with the lives of children and young people.

If the global reach of a human rights agenda has been achieved in a remarkably short space of time (Cmiel, 2004), the international impact of a specifically children's rights agenda since the formal ratification of the UNCRC in 1989 has been even more rapid (James \& James, 2008). The UNCRC is a legal text and, as taken up and enshrined within national law, it has an authority to make demands upon professionals that lead to new responsibilities and accountabilities (Latour, 2013; Evans, 2005). However, the UNCRC only becomes meaningful within professional contexts once this legal text becomes translated within specific policy terms, which are then engaged in practice. In other words, although universal in scope, the UNCRC only 'touches down' when links are made between 
its principles/purposes and the ongoing intergenerational practices where it is enacted.

The focus of this paper is an inquiry into the practices and assumptions that are involved in translating the UNCRC (United Nations, 1989) as a legal text into texts that potentially challenge and inform change within educational situations where children and adults meet. A key argument is that multiple practices of translation are necessary if the UNCRC is to be taken up in situations of practice. This is because the Convention is a legal text and its implications for practice are not immediately apparent. The kinds of texts that we have in mind here, where this kind of translation is performed, include professional codes of ethics, professional standards, policy guidance and the kinds of indicators that school inspectors use in relation to accountability and performance review. These texts also include the construction of various indicators that are used in the context of national comparison (see below). It is through these kinds of texts that the UNCRC is mediated into practice. To date, there has been relatively little critical debate as to the kinds of translations that are performed in the name of the UNCRC, so as to render this legal text relevant for practice. We argue that such debate is desirable if the critical import of the UNCRC is to be realised beyond the performance of a pre-established consensus. Consensus, we contend, is problematic if the cost of this is a refusal to discuss different ways in which the UNCRC might be translated into situations of practice. The aim of the paper is therefore to highlight this process of translation and to identify some of the limitations inherent within present translations and mobilisations of the UNCRC. 
On the basis of this diagnosis, a series of ethical considerations will then be raised to inform ways in which the UNCRC is mediated into practice in future.

Given the international reach of the UNCRC, it is of little surprise that a major concern of policy makers in recent years has been the production of consensus given the desire to ensure that educational contexts, inter alia, become consistently rights-informed (Reynaert et al. 2009, 2012; Quennerstedt, 2013). The translation of the UNCRC as an international legal text into local forms of practice can be represented diagrammatically as follows:

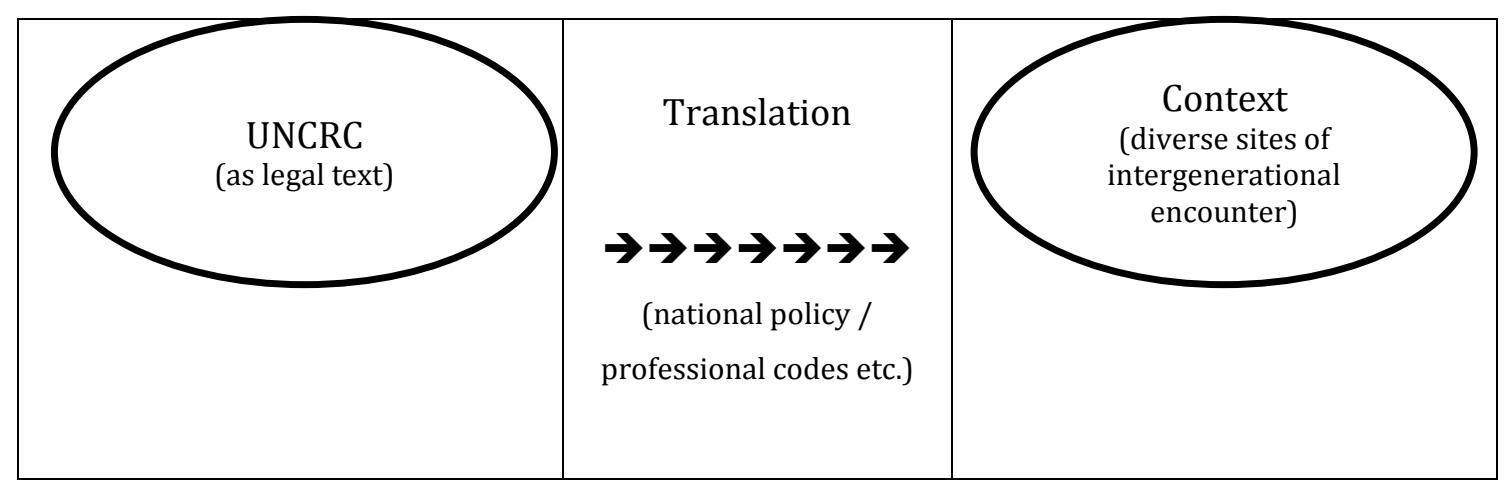

Figure 1: The Translation of International Legal Text into Policy

Beyond remarking that the establishment of a consensus has been a primary focus of concern for policy makers, the nature of the consensus produced and its consequences for practice has not, to date, been a major focus of critical analysis. Furthermore, for the most part, there has not been much discussion regarding the possibility of conceiving other kinds of translation, mediated through, for example, acknowledging different theories and engaging different rubrics ${ }^{1}$. 
This paper is also concerned with identifying the forms of accountability that current translations of the UNCRC have engendered. Since the ratification of the Convention there has been a major effort to ensure a world-wide consistency of implementation. This we characterise as an 'International Children's Rights Economy'. We question some of the effects of this economy and argue that unless there is critical scrutiny of these processes of translation, the professional enactment of children's rights within policy is liable to be reduced to a technical process. Our analysis further suggests that the present international economy of children's rights is a closed system that is not open to change. In the light of this diagnosis we make a case for greater openness to questioning, especially in relation to ethical issues, and, in the light of this, to orientations that might enable a thinking and practice otherwise.

In the first part of this paper we outline how a consensus apropos children's rights is currently constructed, and point to certain problems with this. Based on our arguments, we develop a diagram with which the 'vehicles and vocabularies' (Moon, 2012: 877) through which children's rights discourse is translated, expressed and enacted can be illuminated. In Part II we critically analyse this ordering so as to highlight and discuss some of the limitations inherent within this. Here, we focus upon one problematic in particular: how ethical responsibility is discharged within this international economy. Raising this issue enables us to identify the ethical limitations of the present framing and to ask how this work of translation could be performed differently, in ways that might acknowledge the significance of ethical dimensions in particular. 


\section{1: The International Children's Rights Economy}

\subsection{Translating Children's Rights: from law to professional practice}

The UNCRC was the outcome of a ten years period of deliberation that culminated in a 'signature event' (Gherardi \& Landri, 2014) in which multiple representatives signed a legal agreement that was to become the most widely ratified international human rights treaty in history. Whilst this was a formidable achievement, it then became necessary to identify ways in which the UNCRC might have global impact within the many diverse settings of inter-generational encounter. In identifying some of the issues and constraints faced in mobilising the UNCRC in situations of practice it is first necessary to acknowledge the kind of text that was agreed upon by the signatories in 1989.

The Convention is a specific kind of legal agreement; as such, it is situated within a legal mode that is quite distinct from other discursive practices, with its own characteristic ways of determining what is an appropriate legal expression and enactment $^{2}$ (Latour, 2015; 2009). Thus law:

...has its own force [...] its own mode of veridiction, certainly different from that of Science, but universally acknowledged as capable of distinguishing truth from falsity in its own way. (Latour, 2013: 358-9, emphases in original text)

It is the failure to take due account of differences between distinct modes of existence that has, in practice, led to quite a lot of confusion, especially when a way of doing things appropriate to one mode is inappropriately assumed of 
another. An example here is the erroneous assumption that law is primarily concerned with correct representation, as is the case with a scientific mode of existence. Within its own terms, law is primarily concerned with due legal process, and many misunderstandings arise from a failure to acknowledge such differences.

It is sufficient for our present purposes to note that the UNCRC, as a legal text, requires for its mobilisation, translation within other-than-legal terms. According to Readings (1992, p.183), translation derives from the Latin translatio, which means to 'lift across, move, transfer'. In the process of transfer or bridging, change takes place, and understanding how this is performed in practice is clearly desirable, as it will have a significant bearing upon what is achieved. Once the specific stages involved in this work of bridging are identified, it then becomes possible to identify both the different kinds of translations that are performed and the kinds of assumptions that these imply.

An especially clear illustration as to how such an investigation into translation might be carried out in practice can be found in Latour's (1999) study where he accompanied a variety of scientists working on the edge of the Amazon rainforest. As part of their work, the scientists identified different kinds of soil that were present in the area under investigation. Latour tracked the translations involved as scientists went about their work of translating the materiality of soil into data. Various technologies and ordering practices were used, such as charts to compare soil types and tests to determine, for example, the acidity of a soil sample. This in turn enabled the scientists to identify soil 
samples through signs, that enabled their further translation into concepts that could became elaborated in written texts. These academic papers were then circulated, engaged with, and taken up by readers at a considerable remove from the contingent circumstances of their initial production. At each stage of the translation, something was gained in terms of generalisability, but something was lost in terms of the specificity of location and materiality. Latour also noticed that as each stage in this process was achieved, the successive translations that were a condition of its possibility, became invisible.

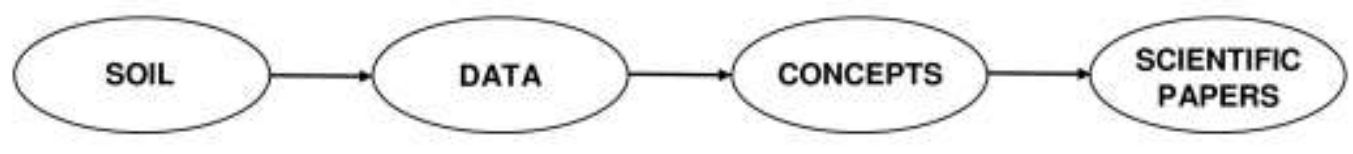

Figure 2: The Translations from Material to Abstract Theory

As a consequence of this empirical work, Latour (1999: 56) noted that, '[w]e never detect the rupture between things and signs'. The connection between a word and state of affairs 'out there' becomes so familiar and habitual that we forget both how contingent that connection is, and the work necessary to stabilise this relation. If this is the case as regards the translations between materials and discourse, it is perhaps even more marked when we consider translations between one mode of existence (such as law) and another (such as ethics). We will say a little about this before considering some of the implications for the specific case of translations involved in the mobilisation of children's rights from international Convention to impact in diverse situations of intergenerational encounter. Many of the insights informing Latour's study are 
helpful in moving beyond the invisibility of translations. It is noteworthy, however, that the multiple translations involved in mobilising the UNCRC as an international legal text to specific situations of practice and encounter would appear to be heading in the opposite direction of travel from Latour's (1999) study, in so far as our focus of concern here is with the move from (more) universal to the (more) specific.

\subsection{Translation: between Modes of Existence}

According to Latour (2013) significant - if frequently unacknowledged translation processes take place in moving from one mode of existence, such as a legal mode, to another, such as politics, religion or morality. Drawing upon concepts developed by Austin (1978) on the work that language does, Latour argues that the imposition of the language and practices associated with one mode of existence within the context of another, leads to infelicity conditions. In other words, the performance is inappropriate to its setting: something is amiss. If, as we have seen, law is primarily concerned with due legal process, misunderstandings are likely to arise both from a failure to acknowledge the distinctiveness of law as a particular mode, and from a failure to acknowledge the translations that are necessary if this mode is to be translated into otherthan-legal situations of practice. So, for example, if a code of ethics is to be derived from a legal Convention, this will necessarily involve practices of translation; law and ethics are different modes of existence, each having different grammars of practice. 
The argument being made here in regard to children's rights is that some such work of translation is necessary if a legal text (the UNCRC) is to be taken up within situations of professional practice. This work of translation involves a number of stages. In the first instance, it involves translating the UNCRC articles into the context of specific national legal systems. It then requires a much more diffuse and complex dissemination into professional policy discourse, so that rights-informed perspectives can be taken up by practitioners. This, in part, explains why a major emphasis since the UNCRC's inauguration has been its consistent enaction, rather than a critical interrogation of its imbrication with theory (James, 2007).

The urgency associated with the call to assure that children and young people live within contexts that acknowledge their rights has tended to take precedence over theoretically informed discussions as to precisely what kinds of translations this might mean in practice. Another way of putting this is to point to a certain tension between, on the one hand, activists who are keen to promote rightsinformed practice, and theorists, on the other, who are concerned with raising questions as to how this might be effected. Such tensions might be seen as characteristic of the field to date. Thus, for example, whereas activists would be keen to extend opportunities for children and young people to be consulted in matters that concern them, theorists have questioned a number of tropes associated with children's rights discourse, such as 'voice' as having been mobilised somewhat uncritically in practice, without a critical reading of some of the epistemological assumptions that these entrain (James, 2007; I'Anson 2013, 
2016). As Moon (2012: 876) observes:

...credo is manifest in form, and an examination of form reveals something about the relationship between the 'world view' of human rights organisations and the 'styles of thought' that shape and inform their representations.

Given these considerations, it is therefore desirable to attend rather more critically to the means through which children's rights discourse is translated, expressed and enacted.

According to Kaime (2010: 637), a key challenge for children's rights advocates 'is how to translate the treaty's prescriptions into robust protection for children everywhere'. In the light of this twin concern with advocacy for children's rights and consistency of their enaction, it is perhaps not surprising that there has been - and continues to be - an enormous amount of literature focussed upon standard setting, implementation, and subsequent monitoring. As Ennew and Miljeteig (1996) observe, just because a treaty has been ratified by a given state, it does not follow that rights are effectively mobilised in practice. It is because of widespread concerns regarding the ways in which rights are mobilised worldwide that some kind of independent monitoring has been deemed necessary. The idea is that through such monitoring, states can be held accountable for the actions that are taken apropos the implementation of rights within their jurisdiction. Within the context of a project concerned with translating rights into practice, Monteith and O'Connor Bones (2013) argue that indicators have certain affordances, and can be used to:

- describe the condition of children's lives 
- enable comparisons

- monitor

- inform policy-making

- inform service planning, development and delivery

- reinforce accountability

- evaluate

- lobby for change.

Indeed, such has been the call for this kind of translation and monitoring that Stammers (1999) refers to this process as part of a 'global children's rights industry'. In their subsequent literature review on research in children's rights, Reynaert et al. (2009) have taken up this description as the third part of their extensive overview. Here, Reynaert et al. (2009: 528) observe:

The debate on children's rights has become a technical debate on the most effective and efficient way to implement children's rights, how best to monitor this implementation and how this can be organized. This is preeminently a positivistic representation of children's rights. The consensusthinking in children's rights that lies at the heart of this 'technicalization' has 'closed' the debate on children's rights. What the children's rights discourse lacks is critique (Evans, 2005) meaning reflection on the legitimacy and relevance of children's rights as the new norm in dealing with children.

What this 'technicalization' process overlooks is precisely the various translations that necessarily play a role in this mobilisation, and their effects in 
terms of wider accountability agendas. Moreover, according to Carvalho (2008), the generality of rights does not lend itself well to translation into specific indicators that are capable of measurement. In this connection, Thede (2001) has raised significant concerns as to how, precisely, these translations between rights and indicators are achieved. She also notes a tendency for the process of fabrication to become invisible once it has been made. In Thede's (2001, p. 259) words:

The contested nature of any particular measurement is such that the consolidation of several measurements into an 'index' for comparative purposes is risky and misleading. Our approach to quantitative measurement is therefore highly circumspect. In addition to [...a number of] practical problems [...], there is a disquieting lack of theory concerning the translation of a 'right' into a measurement.

Socio-material theories, such as the work of Latour drawn upon above, would, we contend, contribute to such a theorisation, and enable a more critical exploration of the complex practices and materialities that are conjoined in this work. However, whilst such a theorisation would indeed surface the various practices and assemblages involved in the production of indicators, it would most likely further problematise such indicators, in so far as assumptions informing their current construction would also be brought to light and in to question.

The foregoing discussion has made a number of other points, which we draw together before developing our argument further: 
(i) the movement from legal text to enaction in practice necessarily involves some kind of translation, and

(ii) once this process has been achieved it is often rendered invisible, and thus

(iii) no longer open to critique or contestation.

In view of this, critics have suggested that the translations that currently inform practice,

(iv) amount to a technicalization of children's rights.

A further point to note, however, is that

(v) this process of translation is multiple: in other words, the transition from legal text to professional enaction and subsequent monitoring, involves a series of distinct translations, and not just one.

In the following section we identify a series of such translations which we collectively characterise as an 'international economy of rights'. The intention here is to identify some of the key steps involved in the translation from legal convention, to national policy context and hence to contexts of enaction and the kinds of accountability regimes that are in place. These typically involve the production of a series of indicators that professionals are required to acknowledge and address in the their work situations, as we have seen.

\subsection{The International Economy of Children's Rights}


In order to further differentiate the translation process that was initially described in Figure 1, a diagram displaying what we term an international economy of children's rights is presented below (Figure 3). The diagram summarises at an abstract level of description the various stages that together constitute the means of translation of the UNCRC into state policy systems, and the forms of accountability that these generate in practice situations.

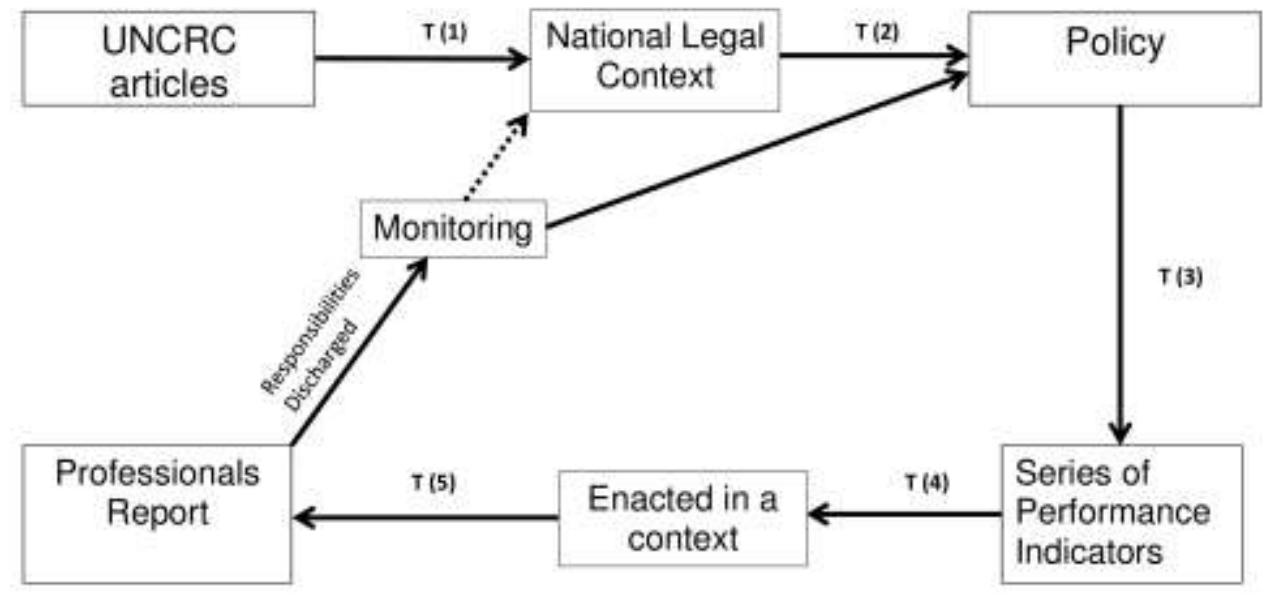

Figure 3: The International Economy of Children's Rights $T=$ translation

The diagram identifies 5 specific translations that are necessary:

Translation 1 (T1) The legal translation of the UNCRC articles into member states' legislative systems.

Translation 2 (T2) The translation from legal instantiation to policy discourse at multiple levels (state, regional, local levels etc.). 
Translation 3 (T3) The translation of policy into organisational and professional expectations, typically through the construction of a series of performance indicators. In practice these might be designated as, for example, 'quality indicators' as they become distributed across multiple forms of professional accountability - e.g. Teacher Professional Standards (GTCS, 2013).

Translation 4 (T4) The translation of organisations and professionals in engaging with these indicators in their practice.

Translation 5 (T5) The translation in professionals' reports on the success, or otherwise, of their mobilisation of rights as indicators.

Professional ethical accountability is produced through this translation process, whilst professional responsibility is discharged through the reporting process that is integral to the economy.

\section{Problematising the International Economy of Children's Rights}

Having identified the multiple translations that are involved in the mediation of the UNCRC into situations of practice, we now take a critical look at how this economy promotes a 'consensus thinking'. The identification of some of the economy's inherent limitations serves as a prelude to introducing a series of 
ethical considerations that might inform thinking about new ways in which the UNCRC as authoritative legal text might be engaged.

A critique of this economy helps to surface some of its constitutive features, and in particular, the identification of translations involved in the mobilisation of children's rights within specific organisational and professional domains. To the extent that the five translations into practice identified in Figure 3 are hidden from view, they become naturalised and invulnerable to critique. The absence of theoretical scrutiny in relation to translations from rights to indicators, means that the resultant economy of rights is likely to be one in which deeply embedded assumptions are continuously, and unknowingly, re-inscribed.

\subsection{Consensus Thinking: assumptions, values and logics}

The identification of the different stages that punctuate this process (T1-5 in Figure 3) as an economy, is to foreground the work of production involved, and

the multiple relations and exchanges that are involved in making that production possible. Once the multiple, different points of translation are identified, it then becomes possible to inquire in to the various assumptions, values and logics that inform how these translations are performed in each case, whilst keeping in mind their location within an overall process. Perhaps the first point to note is that the UNCRC is presented as an achieved consensus of the nation states and other representatives that took part in the ten years of its formulation, from 1979-1989. Secondly, the international legal text thus formulated is a text of authority, with the capacity to potentially challenge situations where rights are 
infringed. It is assumed, in other words, that the effective mobilisation of the UNCRC will have beneficial effects for children: its enaction will be for the 'good' of all children. In the light of this it is, thirdly, necessary to monitor its effective implementation into practice in the diverse sites of intergenerational encounter, to ensure that this good is realised in practice.

The 'consensus thinking' referred to by Reinhardt et al. (2012) has been achieved in part through the multiple translations (T1-5 in Figure 3) being rendered invisible. The effect of this is to privilege alignment with a given translation over professional and inter-generational dialogue about the form that these translations might take: consensus-forming is prioritised over the uncertainties associated with opening this up for deliberation. One of the effects of this is that the UNCRC, as authoritative text, appears to transcend the contingencies associated with its production, dissemination and mediation. Opening up such translations to questioning is desirable given the tendency in discourse on professional responsibility to simply assume a given translation without inquiring into how this might be taken up and possibly re-worked in the light of specific circumstances (Fenwick, 2016). This would then enable the surfacing of the many dilemmas facing professionals as they negotiate competing priorities in their day-to-day practice.

\section{2:2 Children's Rights: from Morality to Ethics?}

Given the potential scope of the issues raised here we have decided to restrict analysis to a single problematic. Here, we examine how ethical responsibility is 
discharged in relation to the series of translations that mediate the UNCRC into organisational and professional practice. Our concern, in short, is to problematise the ethical limitations of the existing international economy of children's rights and to investigate how raising this question might in turn afford the possibility of thinking and practising in ways that are open to different conceptions of 'the good for children'.

The choice of this particular aspect for consideration is due to the fact that the ethical dimensions in this economy are especially settled: put bluntly, both the present and future 'good' for children and young people is rendered already calculable. In other words, the 'good' for children is resolved into an adequate performative response to the indicators. Once the indicators have been effectively taken up and performed, adult responsibility is discharged. This creates a horizon of possibility that is known, and exhaustively mapped in advance. To this extent, the translations effected (through the processes identified in figure 3) are from UNCRC as legal code to moral code.

In this connection, it is noteworthy that Williams (1985) distinguishes between morality and ethics; morality is essentially where ethical questions are resolved in particular ways, through a specific code, rule or set of obligations. Ethics, on the other hand, is where the process of questioning in relation to right conduct is opened up and decided through deliberation. A condition for a distinctively ethical approach is that the movement from presenting situation to enactment is interrupted: a gap is opened up that enables the possibility of considered practice. Within this gap, thinking becomes possible, and it is such thinking - and 
thus the possibility of acting otherwise - that is characteristic of an ethical approach. Foucault (1991: 388) described this moment of thinking in the following way:

Thought is not what inhabits a certain conduct and gives it meaning; rather, it is what allows one to step back from this way of acting or reacting, to present it to oneself as an object of thought and question it as to its meaning, its conditions, and its goals. Thought is freedom in relation to what one does, the motion by which one detaches oneself from it, establishes it as an object, and reflects on it as a problem.

The possibility of such freedom in relation to action is a key constituent of ethical action as distinct from an approach based upon morality. In so far as an ethical response is concerned with the process of opening up questions as to how relations might be configured in a particular circumstance, some such thinking would appear desirable. However, the present international economy of children's rights, we contend, closes off this possibility in so far as a predetermined resolution of responsibility is entailed. This amounts to the production of a system of morality rather than that of ethics, where the various participants in a situation are given the opportunity to take up questions as to how particular pressing concerns might be worked through. A pre-determined morality removes the challenge of ethical thinking for both adults and young people. The idea, following Arendt (1993: 196), that children might bring 'something new, and something unforeseen by us' to a scene, is not anticipated or accommodated within the terms of a moral accounting. 
It is noteworthy that, within the present economy of children's rights, it is adults who determine both the indicators, as mediators of rights, and the manner in which these are to be deployed (i.e., what counts as a 'successful performance'). In so far as this horizon of possibility is determined by adults, it is perhaps not surprising that some of the performative resolutions are somewhat mundane and indeed marginal to children's matters of concern, such as the actualities of learning and teaching in schools, for example. In this connection, even in relation to the UNICEF Rights Respecting School initiative, Robinson (2014: 19) found that the actual scope for children and young people to make significant decisions was somewhat lacking:

While on the surface relationships may appear to be mutually respectful, the micro-processes at play within schools can work to position pupils as relatively 'powerless' when compared to the adults in schools, with pupils internalising unstated assumptions that certain aspects of school organisation, policies and practices are not open to be challenged by them.

Be that as it may, it is in relation to these specific instruments for measurement that adult accountability agendas in relation to children's rights are produced. The various performance indicators that are constructed as a consequence, become the specific textual forms through which the rights agenda is mobilised and adult responsibilities discharged. Whilst this enables organisations to measure the extent to which particular agendas have been achieved, critical questions remain concerning the kinds of translations that are being performed and the ethical limitations inherent in such economies of practice. 
The current economy of rights approach characterised above, also leads to a realisation of rights that is both ethically flat and undifferentiated. That is to say, there is little, if no sense of the complexity of ethical work that may be necessary in order to realise a particular good: the impression is given that ethical practice involves an unproblematic 'taking up' of the indicators into practice, as part of a policy process that is simply 'rolled out' (Edwards et al., 2009). This assumes, amongst other things, that the subject is unaffected by their practice and that the ethical work necessary is simply technical: there is no suggestion - and hence no analysis of - the kinds of work that the subject may have to undergo to become more attentive and responsive to another. This might include, for example, the effort to de-centre the subject's own interests, and, more radically, place those of another in their stead. A very different ethical reading becomes possible once it becomes possible to inquire into the kinds of subjects that are produced through particular discourses and practices.

Such inquiry therefore gestures towards ways in which the UNCRC as legal text might be translated in ways that radically extend the scope of children's rights in practice. Beyond the limitations that we have identified in a technical resolution, there are opportunities here for translations that issue in new forms of dialogue that are responsive to children and young peoples' present concerns, whilst also being orientated to new and different futures that are co-constructed on such an ethical basis.

\section{Conclusion}


Barad (2007: 144) has argued that it is necessary 'to contest and re-work what matters' lest something important be excluded along the way. In this paper we have argued that it is desirable to surface assumptions that inform the work of translation involved as the UNCRC as an international legal text is mobilised in situations where children's rights is practised to date and that such inquiry enables some purchase upon the limitations inherent in present framings and mobilisations. More specifically, we have problematised the current international children's rights economy and, through identifying the multiple translations that are implicated in its performance, we have located a number of critical junctures in relation to which questions might be engaged to think and practice in different terms.

Given the importance of some understanding of the 'good' to thinking and practice within the field of children's rights, this paper has foregrounded some of the ethical limitations of current ways of going on. An exploration of the ethical implications for mobilising rights points to issues that go well beyond the limitations of current translations into performance indicators. Such an orientation is both present and future-oriented and explores, as one ethicist has put this, 'the ways that people work on themselves so as to be able to realise the good in the creation of their moral selves'; to this extent, a focus is upon 'the ways people come to believe that they can successfully create a good beyond what is presently given in their lives' (Robbins, 2013, p. 458). The focus upon such ethical imaginaries opens up new and exciting ways in which the legal text of the UNCRC might be translated in ways that promote the enactment of rights 
that are potentially more fully inclusive of children and young people.

\section{Notes}

1 There are important exceptions to this general statement, and we will subsequently draw upon significant interventions from Thede (2001) Stammers (1999), Reynaert et al. (2009) and others.

${ }^{2}$ Latour's (2013) more recent work recognises that whilst the modern project was much concerned with documenting the lives of non-western subjects, it was rather less effective or interested in understanding the principles and assumptions that informed its own practices. At the heart of Latour's project is therefore an anthropology of moderns, with the purpose of discerning the animating principles that inform distinct forms of discursive practice, which are named 'modes of existence'. Latour distinguishes 14 distinct modes of existence, each with its characteristic ways of going on. Within this set of modes of existence, law is a distinct mode with its own ways of proceeding.

\section{References}

Arendt, H., "The Crisis in Education", in Between past and future: Eight exercises in political thought (New York: The Viking Press, 1993: 173-196).

Austin, J. L., How to do Things with Words (Oxford: Oxford University Press, 1978). 
Barad, K., Meeting the Universe Halfway: Quantum Mechanics and the Entanglement of Matter and Meaning (Durham and London: Duke University Press, 2007).

Carvalho, E., "Measuring Children's Rights: An Alternative Approach", International Journal of Children's Rights, 16 (2008): 545-563.

Cmiel, K., "The Recent History of Human Rights”, The American Historical Review, 109 (1) (2004): 117-135.

Edwards, A., Daniels, H., Gallagher, T., Leadbetter, J., and Warmington, P., Improving Inter-professional Collaborations: Learning to do multi-agency work (Abingdon \& New York: Routledge, 2009).

Ennew, J. and Miljeteig, P., "Indicators for children's rights: progress report on a project", International Journal of Children's Rights, 4 (1996): 213-236.

Evans, T., “International Human Rights Law as Power/Knowledge”, Human Rights Quarterly, 27 (3) (2005): 1046-68.

Fenwick, T. J., Professional responsibility and professionalism : a sociomaterial examination (Abingdon, Oxon: Routledge, 2016).

Foucault, M., "Polemics, politics and problemizations”, in P. Rabinow, (ed.), The Foucault Reader (Harmondsworth, Middlesex: Penguin, 1991).

Gherardi, S. and Landri, P., (2014) “'I Sign, Therefore I am' (Un)stable Traces of Professional Practices", Professions and Professionalism, 4 (2).

GTCS (General Teaching Council, Scotland), The Standards, (n.d.) Available at: http://www.gtcs.org.uk/professional-standards/professional-standards.aspx I'Anson, J., "UNCRC at 25: a critical assessment of achievements and trajectories with reference to educational research", in J. Gillett-Swan and V. Coppock, (eds.), 
Children's Rights, Educational Research and the UNCRC past, present and future, (Oxford: Symposium, 2016: 17-37).

I'Anson, J., “Beyond the Child's Voice: towards an ethics for children's participation rights", Global Studies of Childhood 3 (2) (2013): 104-114.

I'Anson, J., “Childhood, Complexity Orientation and Children's Rights: enlarging the space of the possible?", Education Inquiry, 2 (3) (2011): 373-384.

James, A. and James, A. L., European Childhoods: Cultures, Politics and Childhoods in Europe (Basingstoke and New York: Palgrave Macmillan 2008).

James, A., “Giving Voice to Children's Voices: Practices and Problems, Pitfalls and Potentials", American Anthropologist, 109 (2), (2007): 261-272.

Kaime, T., "Vernacularising' the Convention on the Rights of the Child: Rights and Culture as Analytic Tools", International Journal of Children's Rights, 18 (4) (2010): 637-653.

Latour, B., "The strange entanglement of jurimorphs", A chapter prepared for a volume edited by K. McGee, Bruno Latour and the Passage of Law (Edinburgh: Edinburgh University Press 2015). Available at: http://www.brunolatour.fr/node/614 Latour, B., An Inquiry into Modes of Existence: An Anthropology of the Moderns (Cambridge, Massachusetts, and London: Harvard University Press 2013). Latour, B., The Making of Law: An Ethnography of the Conseil d'Etat (Cambridge and Malden, MA.: Polity Press 2009).

Latour, B., Reassembling the Social - An Introduction to Actor-Network-Theory (Oxford: Oxford University Press 2005).

Latour, B., Pandora's Hope: Essays on the Reality of Science Studies (Harvard University Press 1999). 
Monteith, M. and O'Connor Bones, U., "Developing Child Rights Indicators",

UNESCO Centre, University of Ulster (2013). Powerpoint available at:

http://www.niassembly.gov.uk/assembly-business/research-and-informationservice-raise/knowledge-exchange/knowledge-exchange-seminars-series-2/

Moon, C., "What One Sees and How One Files Seeing: Human Rights Reporting, Representation and Action", Sociology 46 (5) (2012): 876-890.

Quennerstedt, A., “Children's rights research moving into the future: challenges on the way forward, The International Journal of Children's Rights 21 (2) (2013): 233-247.

Readings, B., “Pagans, Perverts or Primitives?”, in P. Dhillon and P. Standish (eds.), Lyotard: Just Education (London and New York: Routledge, 1992). Reynaert, D., Bouverne-De Bie, M. and Vandevelde, S., "Between 'believers' and 'opponents': Critical discussions on children's rights", International Journal of Children's Rights 20(1) (2012): 155-168.

Reynaert, D., Bouverne-de Bie, M. and Vandevelde, S., “A review of children's rights literature since the adoption of the United Nations convention on the rights of the child", Childhood 16(4) (2009): 518-534.

Robbins, J., "Beyond the suffering subject: toward an anthropology of the good", Journal of the Royal Anthropological Institute (N.S.), 19 (2013): 447-462.

Robinson, C., "Developing Mutually Respectful Adult-child Relationships in Schools: Is this a reality experienced equally by all pupils?", Research Intelligence, British Educational Research Association (BERA), Issue 125 (2014): 18-19. Seymour, J. K., "Not rights but reciprocal responsibilities", in A. Mold and D. Reubi, Assembling Health Rights in Global Context: Genealogies and Anthropologies (London: Routledge, 2013: 23-41). 
Thede, N., "Human Rights and Statistics - Some Reflections on the No-Man'sLand between Concept and Indicator", Statistical Journal of the United Nations Economic Commission for Europe, 18 (2-3) (2001): 259-273.

United Nations, The United Nations Convention on the Rights of the Child (UNCRC), General Assembly resolution 44/25 (20 Nov. 1989) U.N. Doc. A/ RES/44/25. Available at: http://www.ohchr.org/en/professionalinterest/pages/crc.aspx Williams, B., Ethics and the Limits of Philosophy (London: Fontana, 1985). 